\title{
Development and Assessment of a USP Apparatus 3 Dissolution Test Method for Sustained-Release Nevirapine Matrix Tablets
}

\author{
Chiluba Mwila, Sandile M. M. Khamanga, and Roderick B. Walker* \\ Division of Pharmaceutics, Faculty of Pharmacy, Rhodes University, Grahamstown, 6140 South Africa
}

e-mail: R.B.Walker@ru.ac.za

\section{ABSTRACT}

Dissolution testing is a quality control tool used to assess batch-to-batch performance of dosage forms, thereby providing continued assurance of product quality. Analytical methods for the assessment of pharmaceutical product quality must be validated according to regulatory guidelines to ensure that tests are reliable and valid. Agitation rate, mesh pore size, surfactant concentration, and dissolution medium molarity are experimental parameters that may affect nevirapine (NVP) release and were investigated and optimized to ensure that consistent, reliable, and valid results using Apparatus 3 were produced. Agitation rate was investigated to establish an equivalent response to that observed for NVP release using Apparatus 2 at $50 \mathrm{rpm}$. A reciprocation rate of 5-10 dpm produced dissolution profiles that were similar to those observed using Apparatus 2 . An increase in the molarity of the dissolution medium slightly increased the release rate of NVP, and a $50 \mathrm{mM}$ buffer maintained at $\mathrm{pH}$ values mimicking gastrointestinal tract (GIT) conditions was selected for all experiments. With the addition of $2 \%$ sodium lauryl sulfate (SLS) to the dissolution medium, $>80 \%$ NVP was released from the tablets over the test period. The NVP release rate increased with an increase in the mesh pore size; however, the extent of release was not affected by this parameter. Dissolution test samples were analyzed using HPLC, and dissolution methods were validated for NVP stability in the dissolution medium, specificity, linearity and range, repeatability, intermediate precision, and accuracy as defined by ICH. The dissolution method used for testing NVP tablets can be regarded as an appropriate tool for the evaluation of sustained-release (SR) NVP formulations and the impact of formulation composition and product quality attributes on drug release.

KEYWORDS: Nevirapine; sustained release; USP Apparatus 3; design of experiments; dissolution; validation.

\section{INTRODUCTION}

D issolution testing is widely used as a quality control tool for testing the performance of solid oral dosage forms. As much as possible, a meaningful dissolution test should be representative of the physiological conditions to which a dosage form will be exposed to have significant value for predicting in vivo behavior (1). Dissolution testing is the single most important tool for process control and quality assurance of solid oral dosage forms and is used to confirm that product performance is reproducible while meeting all regulatory requirements when product formulation changes are made (1). Apparatus 1 and 2, which are the most commonly used apparatus for dissolution testing of solid oral dosage forms, have also been applied to the evaluation of sustained-release dosage forms (2-6). However, some disadvantages exist when using Apparatus 1 and 2 to assess the dissolution rate of an active pharmaceutical ingredient (API) from modifiedrelease technologies. These apparatus exhibit complex hydrodynamic conditions that are affected by the location

*Corresponding author.

Dissolution

Technologies AUGUST 2016 of the dosage form in the test vessel, and this may have a significant impact on the dissolution rate of the API (1). Apparatus 1 and 2 are also not suitable for testing dosage forms containing compounds with low aqueous solubility as it is sometimes difficult to maintain sink conditions in such tests $(1,7)$. Apparatus 3 has exhibited superior hydrodynamics when compared with Apparatus 1 and 2 and is particularly useful for the analysis of products containing poorly water-soluble drugs, modifiedrelease technologies, and compounds that exhibit $\mathrm{pH}-$ dependent dissolution characteristics (8). Because of the advantages that Apparatus 3 exhibits over Apparatus 1 and 2, particularly with respect to relatively easy medium changes, and as nevirapine (NVP) is a sparingly soluble API, a dissolution test method using Apparatus 3 was developed. This method was applied to the dissolution testing of commercially available Viramune XR 100$\mathrm{mg}$ tablets and novel experimental sustained-release (SR) NVP tablets during formulation development and optimization studies. 


\section{EXPERIMENTAL}

\section{Apparatus and Reagents}

A Vankel Bio-Dis Apparatus fitted with a model VK 750 (Vankel Industries, NJ, USA) digitally controlled water circulation heater to maintain the temperature of the dissolution medium at $37 \pm 0.5{ }^{\circ} \mathrm{C}$ was used for the dissolution testing of all batches of tablets manufactured in these studies. A stability-indicating, validated, isocratic reversed-phase HPLC method was used to analyze all dissolution samples. The HPLC system consisted of a SpectraSERIES P100 solvent delivery module, a Model AS100 fixed-loop autosampler (both Thermo Separation products, San Jose, CA, USA), and a Spectra 100 variable wavelength detector (Spectraphysics, San Jose, CA, USA). Separation was achieved using a Phenomenex $C_{18}$ column $(5 \mu \mathrm{m}, 250 \times 4.6 \mathrm{~mm})$, and chromatograms were recorded on a Model SP4290 Integrator (San Jose, CA, USA). A Manesty B3B 16-station rotary press (Manesty, Knowsley, UK) fitted with four 9-mm diameter stainless steel shallow concave punches was used to compress powder blends into tablets.

All chemicals were at least of analytical reagent grade. Viramune XR commercially available NVP extendedrelease tablets were used for the development and validation of the analytical and dissolution method and were kindly donated by Boehringer Ingelheim Pharmaceuticals Ltd. (Ridgefield, CT, USA).

\section{Methodology}

Formulation Development and NVP Release

A direct compression method was used to manufacture tablets. The NVP tablet formulations contained either Methocel K4M (Dow Chemical Company, Midland, MI, USA), Carbopol 71GNF (Lubrizol Corporation, Wickliffe, OH, USA), or Eudragit RSPO (Evonik GmbH, Rellinghauser, Germany) or a combination of two of the rate-retarding polymers; spray-dried lactose (SuperTab, DFE Pharma, Goch, Germany); dibasic calcium phosphate (DCP) (Emcompress, JRS Pharma, Patterson, NY, USA); microcrystalline cellulose (Avicel PH102, FMC, Philadelphia, PA, USA); magnesium stearate; and talc. The composition of the tablet formulations that were manufactured during development studies is listed in Table 1 (9). NVP release from the development batches was assessed using an Apparatus 3 test method developed and validated in-house. The formulation was optimized using a Box-Behnken design, and the dissolution profiles of the optimized formulation and commercially available Viramune XR 100-mg tablets were compared.
Table 1. Formulation Composition of Experimental and Optimized Batches

\begin{tabular}{|c|c|c|c|c|c|c|}
\hline $\begin{array}{c}\text { Batch } \\
\text { Number }\end{array}$ & $\begin{array}{c}\text { NVP } \\
(\%)\end{array}$ & $\begin{array}{c}\text { Methocel } \\
\text { K4M } \\
(\%)\end{array}$ & $\begin{array}{c}\text { Carbopol } \\
\text { 71GNF } \\
(\%)\end{array}$ & $\begin{array}{c}\text { Eudragit } \\
\text { RSPO } \\
(\%)\end{array}$ & $\begin{array}{c}\text { DCP } \\
(\%)\end{array}$ & $\begin{array}{c}\text { SuperTab } \\
\text { Spray-dried } \\
\text { lactose } \\
(\%)\end{array}$ \\
\hline NVP001 & 33.3 & 30.0 & - & - & 10.0 & 10.0 \\
\hline NVP002 & 33.3 & 25.0 & - & - & 10.0 & 15.0 \\
\hline NVP003 & 33.3 & 20.0 & - & - & 10.0 & 20.0 \\
\hline NVP004 & 33.3 & 10.0 & - & - & - & 40.0 \\
\hline NVP005 & 33.3 & 20.0 & - & - & - & 30.0 \\
\hline NVP006 & 33.3 & 30.0 & - & - & - & 20.0 \\
\hline NVP007 & 33.3 & 10.0 & 5.0 & - & - & 35.0 \\
\hline NVP008 & 33.3 & 10.0 & 10.0 & - & - & 30.0 \\
\hline NVP009 & 33.3 & 10.0 & 15.0 & - & - & 25.0 \\
\hline NVP010 & 33.3 & 10.0 & - & 5.0 & - & 35.0 \\
\hline NVP011 & 33.3 & 10.0 & - & 10.0 & - & 30.0 \\
\hline NVP012 & 33.3 & 10.0 & - & 15.0 & - & 25.0 \\
\hline NVP030 & 33.3 & 33.1 & - & - & - & 25.0 \\
\hline
\end{tabular}

${ }^{a}$ optimized

\section{Preparation of Dissolution Media}

Phosphate buffer $(25,50$, and $75 \mathrm{mM})$ was prepared by accurately pipetting 1.7, 3.4, and $5.1 \mathrm{~mL} 85 \%$ orthophosphoric acid into a 1-L volumetric flask and diluting to volume with HPLC grade water. The $\mathrm{pH}$ of the buffer was adjusted to values of $1.2,1.6,3.4,4.7,6.8$, and 7.2 using a $0.1 \mathrm{M} \mathrm{NaOH}$ solution, after which approximately $250 \mathrm{~mL}$ of each buffer solution was accurately measured and transferred into outer dissolution vessels $(n=6)$ prior to the commencement of dissolution testing. The medium $\mathrm{pH}$ and dissolution time in each vessel were selected to mimic the expected range that a dosage form would be exposed to following oral administration (1).

\section{Factors Affecting NVP release}

\section{Buffer Molarity}

The effect of buffer molarity on NVP release was investigated to identify a buffer of suitable strength for use in testing. Buffers of 25,50 , and $75 \mathrm{mM}$ strength were prepared and titrated to $\mathrm{pH} 1.2,1.6,3.4,6.8$, and 7.2 , then used to generate release profiles that were subsequently compared using the difference $\left(f_{1}\right)$ and similarity $\left(f_{2}\right)$ factors (10) to establish the most appropriate molarity for use in subsequent dissolution studies.

\section{Surfactant Use}

Since NVP is a poorly water-soluble compound, a 50 $\mathrm{mM}$ phosphate buffer test medium of $\mathrm{pH} 6.8$ without and with a surfactant, viz., sodium lauryl sulfate (SLS) 
at concentrations of $0.25 \%, 0.5 \%, 1.0 \%$ and $2.0 \%$, was evaluated to establish the effect of concentration on the dissolution rate of NVP from test formulations.

\section{Agitation Rate}

Most modified-release dosage forms exhibit faster dissolution as agitation rates or speeds are increased. Mild agitation conditions are recommended for dissolution testing to permit the development of test methods that ensure maximum discrimination to detect changes in product performance and to assess the potential impact on dosage form performance following administration. Therefore, as recommended in FIP guidelines (11), it is essential that the appropriate agitation rate or speed of rotation of the basket or paddle, dip rate of the reciprocating cylinder, or flow rate for Apparatus 4 is selected to yield results that exhibit $80 \%$ release of an API by the end of the specified test interval. To determine the appropriate agitation rate or number of dips per minute (dpm) to use for dissolution testing using Apparatus 3, dosage form performance was initially assessed using Apparatus $2(n=6)$ with a $50 \mathrm{mM}$ phosphate buffer (pH 6.8) containing $2 \%$ SLS at $50 \mathrm{rpm}$ and $37 \pm 0.5{ }^{\circ} \mathrm{C}$. Dissolution testing was also undertaken using Apparatus $3(n=6)$ with a $50 \mathrm{mM}$ phosphate buffer $(\mathrm{pH} 6.8)$ with $2 \%$ SLS at $37 \pm 0.5^{\circ} \mathrm{C}$ at reciprocation rates of 5,10 , and $15 \mathrm{dpm}$. The dissolution profiles were compared using the $f_{1}$ and $f_{2}$ factors to identify a dip rate that resulted in a release profile that closely resembled that generated using the conditions described for USP 2 Apparatus.

\section{Mesh Screen Pore Size}

To identify a suitable mesh for use with Apparatus 3 , the effect of mesh size on NVP release was also investigated. The smaller mesh screen pore sizes that were evaluated included 20, 40, and 78 mesh, corresponding to 840, 405 , and $177 \mu \mathrm{m}$, respectively. The resultant dissolution profiles were compared using $f_{1}$ and $f_{2}$, and the appropriate mesh size was selected based on visual inspection of the dissolution process, the amount of NVP released during dissolution testing, and the mathematical comparison of dissolution profiles.

\section{Chromatographic Conditions}

All sample analyses were performed using a validated isocratic HPLC method. The mobile phase comprised acetonitrile and water (44:56). The mobile phase was filtered through a $0.45-\mu \mathrm{m}$ HVLP Millipore membrane filter and degassed under vacuum using an Eyela Aspirator A-2S vacuum pump (Rikakikai Co. Ltd, Tokyo, Japan). The UV detector was set at $284 \mathrm{~nm}$, and the flow rate was 1.0 $\mathrm{mL} / \mathrm{min}$ with an overall run time of approximately $10 \mathrm{~min}$.

\section{Preparation of Working Solutions}

Standard stock solutions of NVP $(1 \mathrm{mg} / \mathrm{mL})$ were prepared by accurately weighing $20 \mathrm{mg}$ of NVP using a Mettler Model AE163 top-loading analytical balance (Mettler, Zurich, Switzerland) and quantitatively transferring the powder into a $20-\mathrm{mL}$ volumetric flask. Approximately $10 \mathrm{~mL}$ of methanol was added, and the solution was sonicated for 10 min using a Branson B12 sonicator (Branson, Danbury, $\mathrm{CT}$, USA). The solution was then brought to volume using mobile phase. Analytical standards were prepared by serial dilution of the stock solution to produce standards of $1,10,20,40,120$, and $240 \mu \mathrm{g} / \mathrm{mL}$ of NVP.

\section{Method Validation and Stability Studies}

The analytical method was validated according to ICH and FDA guidelines (12). Linearity was established using least squares linear regression analysis and establishing the equation for the best-fit line. Precision studies were performed by establishing repeatability (intra-assay precision) and intermediate precision (interday precision). Repeatability was evaluated by determining the \%RSD (acceptance limit of $\leq 2 \%$ ) of the peak height ratios of the standard solutions used to construct the calibration curve $(n=5)$ on a single day. Intermediate precision was established by determining the \%RSD (acceptance limit of $\leq 2 \%$ ) of the peak height ratios of standard solutions $(n=5)$ used to construct calibration curves on three consecutive days. The accuracy of the method was determined by analyzing three samples representing low $(5 \mu \mathrm{g} / \mathrm{mL})$, medium $(100 \mu \mathrm{g} / \mathrm{mL})$, and high $(200 \mu \mathrm{g} / \mathrm{mL})$ concentrations within the calibration range $(n=5)$ and calculating the \%RSD.

The specificity of the method was established by exposing commercially available SR NVP tablets to 50 $\mathrm{mM}$ phosphate buffer ( $\mathrm{pH}$ 6.8) for $2 \mathrm{~h}$. An amount of NVP equivalent to the strength of a single tablet $(100 \mathrm{mg})$ was transferred into the outer cylinders containing $250 \mathrm{~mL}$ of the dissolution medium maintained at $37.0 \pm 0.5^{\circ} \mathrm{C}$ ( $n$ $=3$ ), stirred with a glass rod for $10 \mathrm{~min}$, and then left to stand for a further $2 \mathrm{~h}$. The solutions were stirred for an additional $5 \mathrm{~min}$ and then filtered using a $0.45-\mu \mathrm{m}$ HVLP Millipore nylon filter membrane prior to analysis using a validated RP-HPLC method (13). The chromatograms from solutions of NVP prepared from powdered tablets were compared with that of a standard solution of NVP to determine if additional peaks were present and if these interfered with the separation of the peaks for NVP and the internal standard. 


\section{Stability of Sample Solutions in Dissolution Media}

The stability of NVP in $50 \mathrm{mM}$ phosphate buffer covering the $\mathrm{pH}$ range that was used in these studies was assessed by exposing $100 \mathrm{mg}$ of pure NVP to dissolution fluid and storing at $37.0 \pm 0.5{ }^{\circ} \mathrm{C}$, room temperature $(22.0$ ${ }^{\circ} \mathrm{C}$ ), and in a refrigerator between 2 and $8{ }^{\circ} \mathrm{C}$ for $48 \mathrm{~h}$. The samples were then analyzed, and the percentage recovery determined at 0,24 , and $48 \mathrm{~h}$ following storage. ANOVA was used to analyze these results and estimate an appropriate storage time for samples prior to analysis.

\section{RESULTS AND DISCUSSION}

\section{Concentration of Surfactant}

The selection of an appropriate dissolution medium for assessing the dissolution rate of a sparingly soluble API is challenging as it is often difficult to achieve sink conditions $(8,14,15)$. The addition of a small quantity of a surfactant to the dissolution test medium for testing these compounds has been suggested as an appropriate way to better simulate the GIT environment and to achieve sink conditions in vitro $(14,16)$. The caveat is that the lowest possible concentration of surfactant to achieve $75-80 \%$ API release within a reasonable dissolution test time must be used (17). As expected, increasing the amount of SLS in the dissolution medium resulted in an increased rate and extent of dissolution of NVP as has been reported for other BCS Class II compounds $(14,15,17)$.

Comparison of the dissolution profiles using $f_{1}$ and $f_{2}$ reveals that the dissolution profiles for NVP in media with different concentrations of SLS are different (Table 2) except for those in media with $1 \%$ and $2 \% \operatorname{SLS}\left(f_{1}=14.7\right.$ and $f_{2}=54.8$, respectively). However, visual inspection of the two profiles reveals that the rate and extent of NVP release was greater in the $2 \%$ SLS medium and appears slightly different. Because FDA recommends only the use of $f_{2}(18)$, the profiles would be considered similar. However, the value calculated for $f_{1}$ suggests that the profiles may be different, and since only six dosage units were tested, testing of an additional six units would be necessary to obtain a conclusive outcome. The dissolution medium containing $2 \%$ SLS was selected for further use because the rate and extent of NVP release was greater in it than in all other media and $80 \%$ NVP release was achieved over the 24-h test period used in these studies. Although significant foaming with $2 \%$ SLS may occur at high agitation rates necessitating the use of anti-foaming agents, there was minimal foaming observed at the low agitation rates used, obviating the need for including an agent such as simethicone.
Table 2. Values of $f_{1}$ and $f_{2}$ for the Comparison of Dissolution Profiles in Media with Different Concentrations of SLS

\begin{tabular}{|c|c|c|}
\hline Comparison & $f_{1}$ & $f_{2}$ \\
\hline $0 \%$ vs. $0.25 \%$ & 47.1 & 44.4 \\
\hline $0 \%$ vs. $0.5 \%$ & 66.8 & 37.2 \\
\hline $0.25 \%$ vs. $0.5 \%$ & 13.4 & 63.5 \\
\hline $0.25 \%$ vs. $1 \%$ & 39.8 & 41.6 \\
\hline $0.25 \%$ vs. $2 \%$ & 60.4 & 32.8 \\
\hline $0.5 \%$ vs. $1 \%$ & 23.2 & 50.5 \\
\hline $0.5 \%$ vs. $1 \%$ & 41.4 & 38.2 \\
\hline $1 \%$ vs. $2 \%$ & 14.7 & 54.8 \\
\hline
\end{tabular}

Shaded cells: within specification

\section{Effect of Agitation on Dissolution Rate of NVP}

The $f_{1}$ and $f_{2}$ values calculated following the comparison of dissolution profiles of NVP using Apparatus 3 (test) and Apparatus 2 (reference) reveal that reciprocation rates of $15 \mathrm{dpm}$ resulted in dissolution profiles that were different from those observed using Apparatus 2 operated at 50 rpm $\left(f_{1}=24.5\right.$ and $\left.f_{2}=42.3\right)$, depicted in Figure 1. At lower reciprocation rates of 5 and $10 \mathrm{dpm}$, dissolution profiles generated using Apparatus 3 were similar to those generated with Apparatus 2 using a rotation speed of $50 \mathrm{rpm}$, and the $f_{1}$ and $f_{2}$ values were 6.2 and 70.8 at $5 \mathrm{dpm}$ and 13.2 and 54.6 at $10 \mathrm{dpm}$, respectively. These results correlate with previously reported data (14). Further inspection of the dissolution profiles generated using Apparatus 2 and 3 suggests that $f_{2}$ may improve if dissolution testing is performed using dip rates between 5 and $10 \mathrm{dpm}$. Similar studies undertaken by Rohrs et al. (19) and Klein (20) demonstrated that an agitation rate of $10 \mathrm{dpm}$ using Apparatus 3 resulted in dissolution profiles similar to those observed using Apparatus 2 at $100 \mathrm{rpm}$. Consequently, a dissolution test using Apparatus 3 was performed at $8 \mathrm{dpm}$ and yielded difference and similarity factors of 2.4 and 88.9 , respectively. Therefore, a dip rate of $8 \mathrm{dpm}$ was selected for use in all further NVP dissolution testing. The results also reveal that NVP release from tablets increases with an increase in agitation rate, which has been attributed to a reduction in the stagnant layer surrounding the tablet (14), increased erosion of tablets (21), and appropriate drainage of the dissolution medium (22). Evaluation of the $f_{1}$ and $f_{2}$ factors reveals differences in the dissolution profiles, and these data are summarized in Table 3. The data suggest that large differences in agitation rates yield very different dissolution profiles. Experimental parameters must be defined ab initio to ensure that appropriate product development decisions are based on reliable and valid data. 


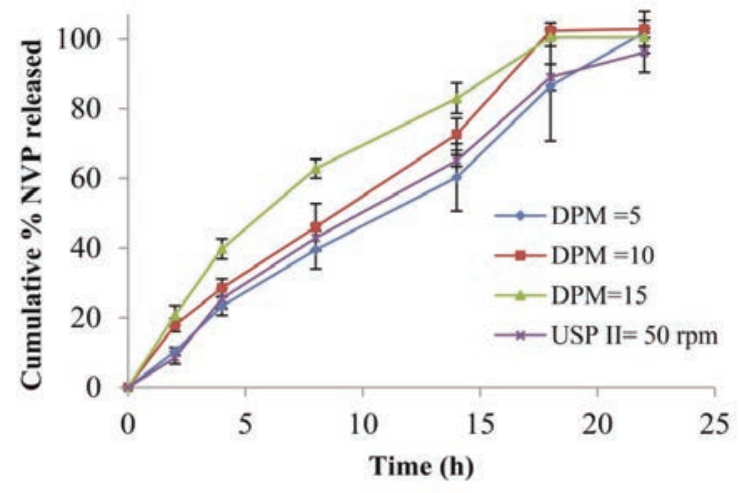

Figure 1. Dissolution profiles of NVP in $50 \mathrm{mM}$ phosphate buffer ( $p H$ 6.8) at different agitation rates.

Table 3. $f_{1}$ and $f_{2}$ Values for the Comparison of Dissolution Profiles at Different Agitation Rates

\begin{tabular}{|c|c|c|}
\hline Comparison & $f_{1}$ & $f_{2}$ \\
\hline $5 \mathrm{dpm}$ vs $10 \mathrm{dpm}$ & 15.7 & 50.5 \\
\hline $5 \mathrm{dpm}$ vs $15 \mathrm{dpm}$ & 30.9 & 37.4 \\
\hline $10 \mathrm{dpm}$ vs $15 \mathrm{dpm}$ & 13.1 & 50.8 \\
\hline $5 \mathrm{dpm}$ vs $50 \mathrm{rpm}$ & 6.2 & 70.8 \\
\hline $10 \mathrm{dpm}$ vs $50 \mathrm{rpm}$ & 13.2 & 54.6 \\
\hline $15 \mathrm{dpm}$ vs $50 \mathrm{rpm}$ & 15.4 & 46.6 \\
\hline $8 \mathrm{dpm}$ vs $50 \mathrm{rpm}$ & 2.4 & 88.9 \\
\hline
\end{tabular}

Shaded cells: out of specification

\section{Impact of Mesh Screen Pore Size}

Studies have been undertaken to investigate the effect of mesh size on the rate and extent of drug release from dosage forms using Apparatus 3 (20). In general, the extent of API release increases with increasing pore size of the top mesh (20). However, while the release of an API depends on the pore size of the top screen due to the impact on drainage of the dissolution medium from the inner tube, drug release does not appear to be affected by the pore size of the bottom mesh size. Studies on the effect of the bottom mesh screen size did not reveal any differences in the overall percentage drug released as observed in a similar study (21). In this study, the lack of a difference in drug release was attributed to the use of an agitation rate of $30 \mathrm{dpm}$. The high agitation rate may have offset the impact of mesh pore size within the first two hours of dissolution testing. In addition, the increased intensity and turbulence within the inner dissolution tube across all dimensions may have increased erosion, fluid drainage, or both. Khamanga and Walker (23) suggested that the hydrodynamics of a system at higher agitation rates results in higher fluid flow velocities that are likely to weaken gel structures that form immediately around a tablet at the commencement of hydration. As the gel layer weakens, the polymeric network structure that retains the integrity of the compact is disrupted slowly, and the layer that ideally acts as the primary retarding region is removed. Consequently, the drug is released more rapidly at higher agitation rates since the surface exposure of the dosage form to the dissolution medium is increased. The results observed in this study may also be attributed to the fact that complete drainage of the dissolution medium from the inner cylinders had occurred, in addition to significant erosion of the tablet regardless of the size of the mesh used.

Analysis of the $f_{1}(11.5)$ and $f_{2}$ (67.1) values calculated for the comparison of dissolution profiles generated with mesh sizes 20 and 40 revealed that the profiles are similar, whereas NVP release profiles generated using mesh sizes 20 and 78 are different, with $f_{1}=32.9$ and $f_{2}$ $=44.9$. The $f_{1}$ and $f_{2}$ values calculated for the comparison of NVP release with mesh sizes 40 and 78 are 19.2 and 53.7 , respectively. Once again, the value for $f_{2}$ indicates that there is similarity between the two profiles, whereas the value for $f_{1}$ suggests that the profiles are different. While the use of only $f_{2}$ is considered in decision making with respect to the similarity of dissolution curves, it has been suggested that both $f_{1}$ and $f_{2}$ values should be used during formulation development studies to facilitate better decision making (24). In addition, the testing of an additional six units may also be useful to ensure that a true difference exists.

Ultimately, a mesh of screen size 20 was selected for use in all further dissolution testing because its drainage of the inner vessel is efficient, which is an important aspect to consider when using Apparatus 3.

\section{Effect of Buffer Molarity on Dissolution Rate of NVP}

Although the dissolution rate of NVP did not appear to be affected by the molarity of the buffer used, slight differences were observed as an increase in the dissolution rate of NVP up to $8 \mathrm{~h}$ when a buffer of high molarity buffer was used (Figure 2). The increase in NVP release with increase in buffer molarity in the earlier stages of the test may be attributed to the weakening of the gel layer surrounding the tablets, thereby increasing the surface area for NVP release (25). However, after 8 $\mathrm{h}$ of testing, the molarity of the buffer did not appear to affect the rate of NVP release. This phenomenon was attributed to the degree of agitation and extent of tablet erosion, which may have had a greater impact on NVP release than buffer molarity. 


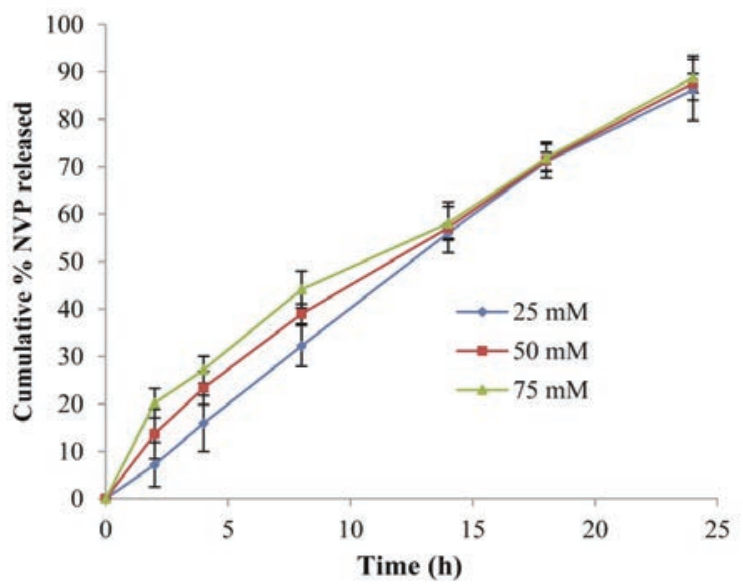

Figure 2. Dissolution profiles of NVP in media of different molarity ( $n=6,8 \mathrm{dpm}, \mathrm{pH} 6.8)$.

Analysis of the $f_{1}$ and $f_{2}$ values reveals that the dissolution profiles are similar, but the value for $f_{2}$ decreased with an increasing difference in molarity of the medium used. Inspection of the dissolution profiles reveals that this phenomenon may be a result of differences in release rates in the initial phases of the test. When higher agitation rates and buffer molarity are used, a salting-out effect of phosphate ions may result in fewer free water molecules being available to solvate the HPMC polymer chains. As such, intermolecular hydrogen bonding within the gel layer is weakened and easily disrupted (27). The buffer molarity did not appear to affect the extent of drug release, and a $50 \mathrm{mM}$ buffer was selected for all future experiments.

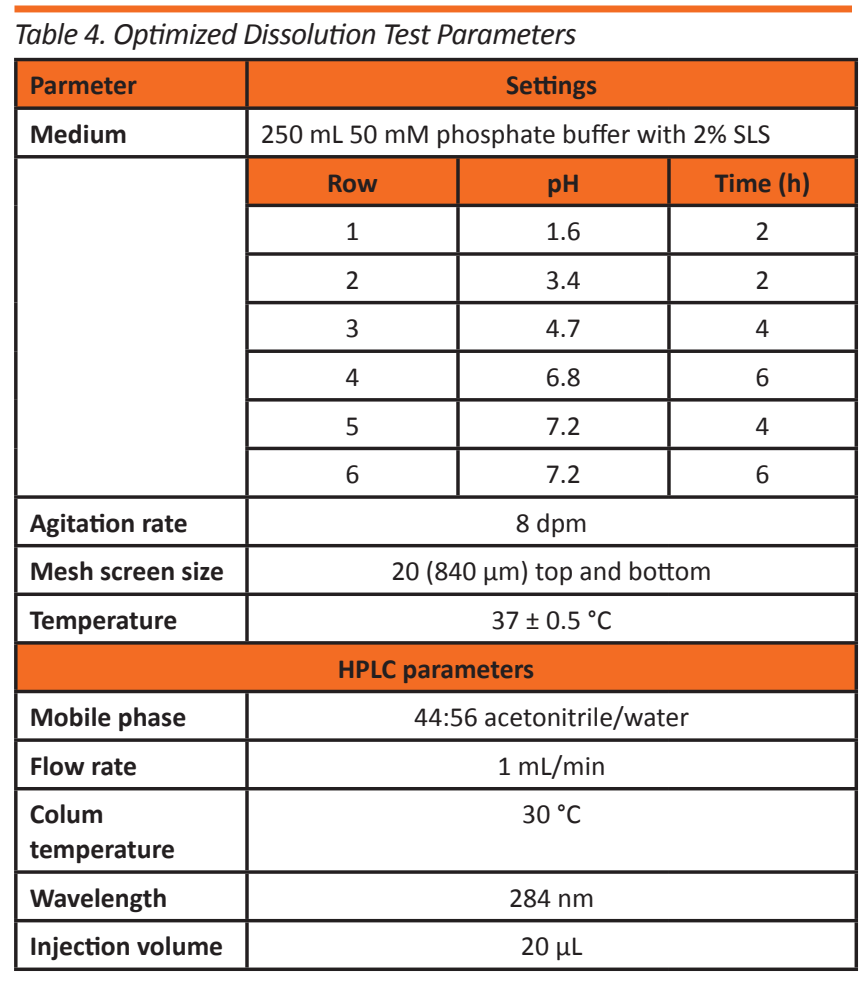

\section{Selection of Dissolution Test Parameters}

Following evaluation of dissolution test parameters that may have had an effect on the release of NVP from test tablets, a specific set of dissolution conditions was identified (Table 4) and used in the analysis of test formulations manufactured during development studies.

The differences in the dissolution profiles generated following dissolution testing of batches NVP003, NVP006, and NVP030 (Figures 3-5) indicate that the test method is discriminatory. The slow rate of release of NVP from batch NVP003 is attributed to the presence of DCP in the matrices as it is insoluble and has been shown to retard API release from matrix tablets by blocking the diffusion of API from matrices by decreasing polymeric matrix erosion $(27,28)$. Consequently, to improve the rate and extent of NVP release, DCP was not included in subsequent formulations.

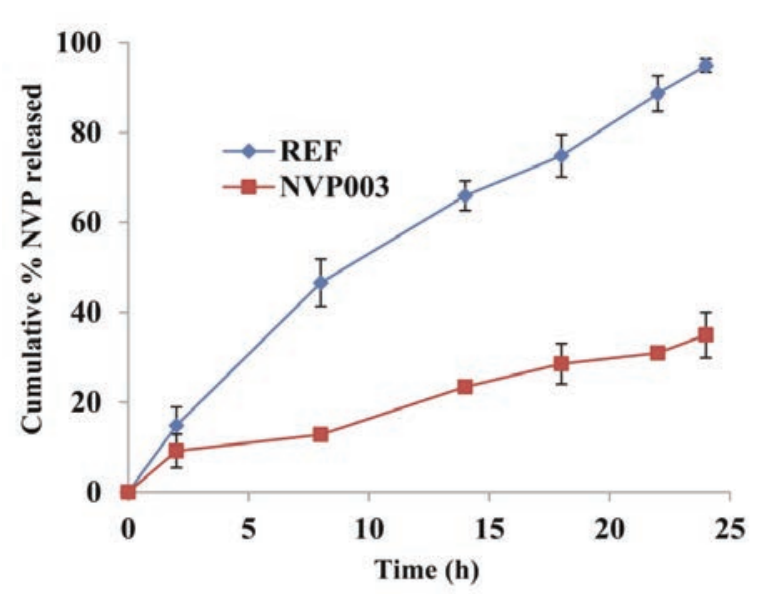

Figure 3. Dissolution profiles of NVP from tablets of batch NVPO03 and Viramune $X R(n=6)$.

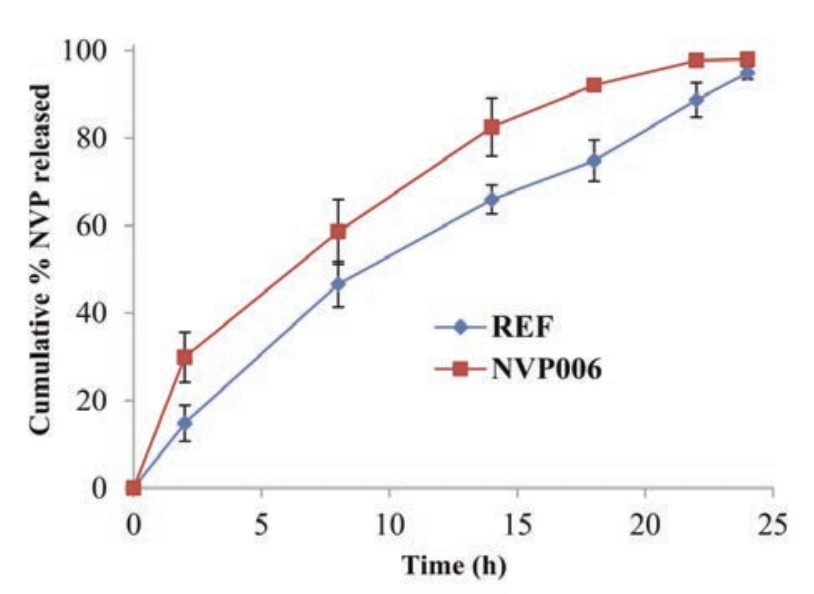

Figure 4. Dissolution profiles of NVP from tablets of batch NVPOO6 and Viramune $X R(n=6)$. 


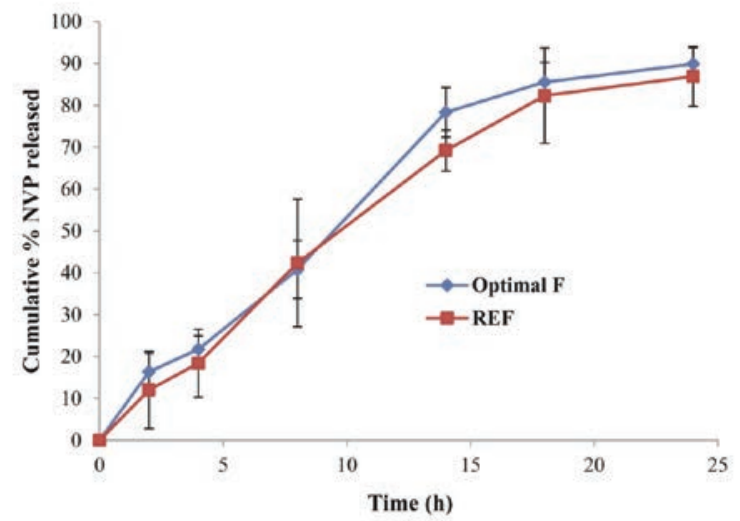

Figure 5. Dissolution profiles of NVP from batch NVP030 and Viramune XR in media of different $\mathrm{pH}$ used to simulate GIT conditions $(n=6)$.

Calculation of the $f_{1}$ and $f_{2}$ values for the dissolution profiles of batch NVPOO6 and Viramune XR tablets yielded $f_{1}$ and $f_{2}$ values of 14.1 and 52.1 , respectively. Thus, NVP release from batch NVP006 was similar to that observed for the reference tablets. Consequently, the batch NVP006 formulation was selected for further development and optimization studies.

Comparison of the dissolution profiles of NVP release from the optimized formulation (batch NVPO30) and Viramune XR yielded $f_{1}$ and $f_{2}$ values of 7.9 and 69.7, respectively, indicating that the profiles were similar.

\section{Method Validation}

The assessment of validation parameters revealed that the method met all recommended criteria; these data are summarized in Table 5. The chromatograms for NVP did not reveal any interference from tablet excipients at the retention time for NVP, thereby indicating that the method is specific for the analysis of NVP.

\section{Stability of NVP in Dissolution Media}

A summary of the percentage recovery for the stability assessment of NVP in dissolution media stored at different temperatures is listed in Table 6. The stability of NVP in $50 \mathrm{mM}$ phosphate buffers of $\mathrm{pH} 1.6,4.7$, and 7.2, which represent low, medium, and high values of the $\mathrm{pH}$ range, was established using ANOVA and percentage recovery. Results suggest that NVP is stable in $50 \mathrm{mM}$ phosphate buffer of different $\mathrm{pH}$ values, indicating that the samples can be stored for up to $48 \mathrm{~h}$ in dissolution media at a temperature of $22^{\circ} \mathrm{C}$ prior to analysis.
Table 5. Validation Results

\begin{tabular}{|c|c|c|c|}
\hline \multicolumn{4}{|c|}{ System suitability } \\
\hline \multicolumn{2}{|c|}{ Resolution factor } & \multicolumn{2}{|l|}{3.82} \\
\hline \multicolumn{2}{|c|}{ Capacity factor } & \multicolumn{2}{|l|}{4.20} \\
\hline \multicolumn{2}{|c|}{ Theoretical plates $(\mathrm{N})$} & \multicolumn{2}{|l|}{19,328} \\
\hline \multicolumn{2}{|c|}{ Tailing } & \multicolumn{2}{|l|}{ none } \\
\hline \multicolumn{4}{|c|}{ Precision } \\
\hline \multicolumn{4}{|c|}{ Intraday } \\
\hline $\begin{array}{l}\text { Concentration } \\
(\mu \mathrm{g} / \mathrm{mL})\end{array}$ & $\begin{array}{c}\text { Standard } \\
\text { deviation (SD) }\end{array}$ & \%RSD & $\begin{array}{l}\text { Acceptance } \\
\text { criterion }\end{array}$ \\
\hline 10 & 0.00028 & 0.671 & \multirow{3}{*}{$\% \mathrm{RSD} \leq 2 \%$} \\
\hline 120 & 0.00083 & 0.158 & \\
\hline 240 & 0.00096 & 0.096 & \\
\hline \multicolumn{4}{|c|}{ Interday } \\
\hline \multicolumn{4}{|c|}{ Day 1} \\
\hline 10 & 0.00017 & 0.275 & \multirow{3}{*}{$\% \mathrm{RSD} \leq 2 \%$} \\
\hline 120 & 0.00068 & 0.084 & \\
\hline 240 & 0.00157 & 0.098 & \\
\hline \multicolumn{4}{|c|}{ Day 2} \\
\hline 10 & 0.00173 & 2.573 & \multirow{3}{*}{$\% \mathrm{RSD} \leq 2 \%$} \\
\hline 120 & 0.00053 & 0.063 & \\
\hline 240 & 0.00188 & 0.118 & \\
\hline \multicolumn{4}{|c|}{ Day 3} \\
\hline 10 & 0.0000825 & 0.123 & \multirow{3}{*}{$\%$ RSD $\leq 2 \%$} \\
\hline 120 & 0.0020070 & 0.242 & \\
\hline 240 & 0.0015850 & 0.101 & \\
\hline \multicolumn{4}{|c|}{ Accuracy } \\
\hline $\begin{array}{l}\text { Concentration } \\
(\mu \mathrm{g} / \mathrm{mL})\end{array}$ & $\begin{array}{l}\text { Concentration } \\
\text { found } \\
\text { (\% Recovery) }\end{array}$ & \% RSD & $\begin{array}{l}\text { Acceptance } \\
\text { criterion }\end{array}$ \\
\hline 5 & $5.03(100.6)$ & 0.801 & \multirow{3}{*}{$\begin{array}{l}\text { Recovery } \\
\text { limit: } \\
95-105 \%\end{array}$} \\
\hline 100 & $100.2(100.2)$ & 0.088 & \\
\hline 200 & $198.6(99.3)$ & 0.112 & \\
\hline \multicolumn{4}{|c|}{ Linearity } \\
\hline \multicolumn{2}{|c|}{ Concentration range $(\mu \mathrm{g} / \mathrm{mL})$} & Equation & $R^{2}$ value \\
\hline \multicolumn{2}{|c|}{$1-240$} & $y=0.0064 x-0.0016$ & 0.9996 \\
\hline
\end{tabular}

\section{CONCLUSIONS}

A dissolution method was developed for assessing NVP release from commercial and experimental products and subsequently met the validation standards for stability of NVP in dissolution media, specificity, linearity, range, repeatability, intermediate precision, and accuracy as defined in the $\mathrm{ICH}$ guidelines. The discriminatory power of the method demonstrated during dosage form development suggests that the method is an appropriate tool to evaluate NVP SR formulations and to establish the impact of formulation composition and product quality 
attributes on NVP release. Furthermore, the method was applied to the dissolution testing of an optimized generic NVP tablet formulation, and the dissolution profile was similar to that of the reference product, Viramune XR $\left(f_{2}=\right.$ 69.7). The results suggest that the method can be applied to the assessment of NVP release for the quality control of experimental and commercially available dosage forms.

Table 6. Stability of NVP in Dissolution Media at Different Temperatures

\begin{tabular}{|c|c|c|c|c|}
\hline \multirow{3}{*}{ Condition } & \multicolumn{3}{|c|}{ \% Recovery } \\
\hline \multirow{5}{*}{$37.0{ }^{\circ} \mathrm{C}$} & $\mathrm{C} \mathrm{h}$ & $24 \mathrm{~h}$ & $48 \mathrm{~h}$ \\
\cline { 2 - 5 } & 1.6 & $98.67 \pm 0.0033$ & $98.52 \pm 0.0094$ & $98.35 \pm 0.026$ \\
\cline { 2 - 5 } & 3.4 & $99.44 \pm 0.0012$ & $98.95 \pm 0.0036$ & $97.77 \pm 0.0012$ \\
\cline { 2 - 5 } & 6.8 & $99.73 \pm 0.0042$ & $99.51 \pm 0.0071$ & $97.42 \pm 0.0058$ \\
\cline { 2 - 5 } & 7.2 & $98.87 \pm 0.0031$ & $99.11 \pm 0.0029$ & $98.98 \pm 0.0083$ \\
\hline \multirow{5}{*}{$2{ }^{\circ} \mathrm{C}$} & 1.6 & $98.88 \pm 0.0018$ & $98.59 \pm 0.0038$ & $97.63 \pm 0.0065$ \\
\cline { 2 - 5 } & 3.4 & $98.67 \pm 0.0092$ & $97.99 \pm 0.0044$ & $98.56 \pm 0.0042$ \\
\cline { 2 - 5 } & 4.7 & $98.91 \pm 0.018$ & $98.72 \pm 0.0029$ & $99.31 \pm 0.0036$ \\
\cline { 2 - 5 } & 6.8 & $98.65 \pm 0.0079$ & $98.93 \pm 0.0085$ & $97.79 \pm 0.0084$ \\
\cline { 2 - 5 } & 7.2 & $99.35 \pm 0.0059$ & $98.69 \pm 0.0024$ & $98.72 \pm 0.0073$ \\
\hline \multirow{3}{*}{$2-8{ }^{\circ} \mathrm{C}$} & 1.6 & $98.93 \pm 0.0022$ & $99.22 \pm 0.0011$ & $98.74 \pm 0.0087$ \\
\cline { 2 - 5 } & 3.4 & $98.77 \pm 0.0037$ & $98.49 \pm 0.0096$ & $99.37 \pm 0.0069$ \\
\cline { 2 - 5 } & 4.7 & $99.20 \pm 0.0055$ & $98.32 \pm 0.0023$ & $98.55 \pm 0.0066$ \\
\cline { 2 - 5 } & 6.8 & $97.94 \pm 0.0039$ & $98.36 \pm 0.0019$ & $98.41 \pm 0.0045$ \\
\cline { 2 - 5 } & 7.2 & $98.13 \pm 0.0068$ & $97.92 \pm 0.028$ & $98.44 \pm 0.0089$ \\
\hline
\end{tabular}

Values reported as mean $\pm S D(n=5)$

\section{CONFLICT OF INTEREST}

The authors declare that there is no conflict of interest.

\section{REFERENCES}

1. Williams, R. O., III; Brown, J. N. Dissolution of Modified-Release Oral Dosage Forms. In Dissolution Theory, Methodology, and Testing; Palmieri, A., III, Ed.; Dissolution Technologies, Inc.: Hockessin, DE, 2007; pp 196-231.

2. Crawley, M. M.; Schroeder, B.; Fredersdorf, A.; Obara, S.; Talarico, M.; Kucera, S.; McGinity, J. W. Physicochemical properties and mechanism of drug release from ethyl cellulose matrix tablets prepared by direct compression and hot-melt extrusion. Int. J. Pharm. 2004, 269 (2), 509-522. DOI: 10.1016/j. ijpharm.2003.09.037.

3. Baun, D. C.; Walker, G. C. Apparatus for Determining the Rate of Drug Release from Solid Dosage Forms. J. Pharm. Sci. 1969, 58 (5), 611-616. DOI: 10.1002/jps.2600580523.

4. Gil, E. C.; Colarte, I. A.; Bataille, B.; Pedraz, J. L.; Rodriguez, F.; Heinämäki, J. Development and optimization of a novel sustained-release dextran tablet formulation for propranolol hydrochloride. Int. J. Pharm. 2006, 317 (1), 32-39. DOI: 10.1016/j.ijpharm.2006.02.049.
5. Reddy, K. R.; Mutalik, S.; Reddy, S. Once-daily sustained-release matrix tablets of nicorandil: Formulation and in vitro evaluation. AAPS PharmSciTech 2003, 4 (4), 480-488. DOI: 10.1208/ pt040461.

6. Azarmi, S.; Roa, W.; Löbenberg, R. Current perspectives in dissolution testing of conventional and novel dosage forms. Int. J. Pharm. 2007, 328 (1), 12-21. DOI: 10.1016/j. ijpharm.2006.10.001.

7. Aiache, J. M.; Aoyagi, N.; Blume, H.; Dressman, J.; Friedel, H. B.; Grady, L. T.; Gray, V.; Helboe, P.; Hubert, B.; Kopp-Kubel, S.; Krämer, J.; Kristensen, H.; Langenbucher, F.; Leeson, L.; Lesko, L.; Limberg, J.; McGilveray, I.; Möller, H.; Qureshi, S.; Shah, V. P.; Siewert, M.; Süverkrüp, R.; Waltersson, J.O.; Whiteman, D.; Wirbitski, E. FIP Guidelines for Dissolution Testing of Solid Oral Products. Joint reprot of the Section for Official Laboratories and Medicines Control Services and the Section of Industrial Pharmacists of the FIP. Dissolution Technol. 1997, 4 (4), 5-14. DOI: 10.14227/DT040497P5.

8. Borst, I.; Ugwu, S.; Bekett, A. H. New and Extended Applications for USP Drug Release Apparatus 3. Dissolution Technol. 1997, 4 (1), 11-16. DOI: 10.14227/DT040197P11.

9. Chiluba, M. The Development and Assessment of Sustained Release Nevirapine Tablets. MSc. Thesis, Rhodes University, South Africa, 2013; pp 138-213.

10. Moore, J. W.; Flanner, H. H. Mathematical Comparison of Dissolution Profiles with an Emphasis on In-Vitro Dissolution Profiles. Pharm. Technol. 1996, 20 (6), 64-74.

11. FIP Guidelines for dissolution testing of solid oral products. Pharm. Ind. 1995, 57 (5), 362-369.

12. Guidance for Industry: Analytical Procedures and Methods Validation for Drugs and Biologics. U.S. Department of Health and Human Services, Food and Drug Administration, Center for Drug Evaluation and Research (CDER), and Center for Biologics Evaluation and Research (CBER), New Hampshire, 2015.

13. Chiluba, M. The Development and Assessment of Sustained Release Nevirapine Tablets. MSc. Thesis, Rhodes University, South Africa, 2013; pp 21-71.

14. Rohrs, B. R. Dissolution Method Development for Poorly Soluble Compounds. Dissolution Technol. 2001, 8 (3), 6-12. DOI: 10.14227/DT080301P6.

15. Zahirul, M.; Khan, I. Dissolution testing for sustained or controlled release oral dosage forms and correlation with in vivo data: Challenges and opportunities. Int. J. Pharm. 1996, 140 (2), 131-143. DOI: 10.1016/0378-5173(96)04561-9.

16. Brown, C. K.; Chokshi, H. P.; Nickerson, B.; Reed, R. A.; Rohrs, B. R.; Shah, P. A. Acceptable Analytical Practices for Dissolution Testing of Poorly Soluble Compounds. Pharm. Technol. 2004, 28 (11), 56-65.

17. Shah, V.P.; Konecny, J.J.; Everett, R. L.; McCullough, B.; Noorizadeh, A. C.; Skelly, J. P. In Vitro Dissolution Profile of Water-Insoluble Drug Dosage Forms in the Presence of Surfactants. Pharm. Res. 1989, 6 (7), 612-618. DOI: 10.1023/A:1015909716312. 
18. Extended Release Oral Dosage Forms: Development, Evaluation, and Application of In Vitro/In Vivo Correlations; Guidance for Industry; U.S. Department of Health and Human Services, Food and Drug Administration, Center for Drug Evaluation and Research (CDER), U.S. Government Printing Office: Washington, DC, 1997.

19. Rohrs, B. R.; Burch-Clark, D. L.; Witt, M. J.; Stelzer, D. J. USP Dissolution Apparatus 3 (Reciprocating Cylinder): Instrument Parameter Effects on Drug Release from Sustained Release Formulations. J. Pharm. Sci. 1995, 84 (8), 922-926. DOI: 10.1002/ jps.2600840804.

20. Klein, S. Evolution of BioDis Methodology: Selection of Adequate Instrument Parameters in Biorelevant Dissolution Test Methods for Modified Release Dosage Forms. Ph.D. Dissertation, Johann Wolfgang Goethe University, Frankfurt, Germany, 2005; pp 117127.

21. Costa, P.; Sousa Lobo, J. M. Influence of Dissolution Medium Agitation on Release Profiles of Sustained-Release Tablets. Drug Dev. Ind. Pharm. 2001, 27 (8), 811-817. DOI: 10.1081/DDC100107244.

22. Li, J.; Yang, L.; Ferguson, S. M.; Hudson, T. J.; Watanabe, S.; Katsuma, M.; Fix, J. A. In vitro evaluation of dissolution behavior for a colon-specific drug delivery system (CODES ${ }^{\mathrm{TM}}$ ) in multi-pH media using United States Pharmacopoeia apparatus II and III. AAPS PharmSciTech 2002, 3 (4), 59-67. DOI: 10.1208/pt030433.
23. Khamanga, S. M. M.; Walker, R. B. The Effects of Buffer Molarity, Agitation Rate, and Mesh Size on Verapamil Release from Modified-Release Mini-Tablets Using USP Apparauts 3. Dissolution Technol. 2007, 14 (2), 19-23. DOI: 10.14227/ DT140207P19.

24. Chaibva, F. A.; Walker, R. B. The Comparison of In Vitro Release Methods for the Evaluation of Oxytocin Release from Pluronic ${ }^{\circledR}$ F127 Parenteral Formulations. Dissolution Technol. 2007, 14 (4), 15-25. DOI: 10.14227/DT140407P15.

25. Neau, S. H.; Chow, M. Y.; Durrani, M. J. Fabrication and characterization of extruded and spheronized beads containing carbopol ${ }^{\circledR}$ 974P, NF resin. Int. J. Pharm. 1996, 131 (1), 47-55. DOI: 10.1016/0378-5173(95)04293-8

26. Joshil, S. C. Sol-Gel Behavior of Hydroxypropyl Methylcellulose (HPMC) in lonic Media Including Drug Release. Materials 2011, 4 (10), 1861-1905. DOI: 10.3390/ma4101861.

27. Sasidhar, R. L. C.; Vidyadhara, S.; Nagaraju, R. Effect of diluents on the release rate of venlafaxine $\mathrm{HCl}$ from matrix tablets. $J$. Pharm. Res. 2011, 4 (1), 153-155.

28. Rekhi, G. S.; Nellore, R. V.; Hussain, A. S.; Tillman, L. G.; Malinowski, H. J.; Augsburger, L. L. Identification of critical formulation and processing variables for metoprolol tartrate extended-release (ER) matrix tablets. J. Controlled Release 1999, 59 (3), 327-342. DOI: 10.1016/S0168-3659(99)00004-8. 